\title{
A formação territorial brasileira e os agentes militares
}

\section{Raphael Neves da Conceição}

\section{Q OpenEdition \\ 1 Journals}

\section{Electronic version}

URL: http://journals.openedition.org/espacoeconomia/17226

DOI: 10.4000/espacoeconomia.17226

ISSN: 2317-7837

\section{Publisher}

Núcleo de Pesquisa Espaço \& Economia

\section{Electronic reference}

Raphael Neves da Conceição, "A formação territorial brasileira e os agentes militares », Espaço e Economia [Online], 19 | 2020, Online since 02 September 2020, connection on 23 September 2020. URL : http://journals.openedition.org/espacoeconomia/17226; DOI : https://doi.org/10.4000/ espacoeconomia.17226

This text was automatically generated on 23 September 2020 .

(C) NUPEE 


\title{
A formação territorial brasileira e os agentes militares
}

\author{
Raphael Neves da Conceição
}

\section{REFERENCES}

Martins, Marco Túlio. História do Pensamento Geográfico: a formação territorial brasileira à luz dos projetos territoriais do Exército (1889-1930). Tese de Doutorado. Uberlândia: Programa de Pós-Graduação da Universidade Federal de Uberlândia (2016)

Desde o fim do século XX tem-se notado o despertar dos geógrafos pela história da geografia e do pensamento geográfico, que analisam prioritariamente os escritos do passado. Um dos períodos mais profícuos para a análise do pensamento geográfico brasileiro está compreendido entre o fim do período Imperial (XIX) e o início da Era Vagas (XX). É nesse sentido que se desenvolve o interesse pela obra História do Pensamento Geográfico: a formação territorial brasileira à luz dos projetos territoriais do Exército (1889-1930) do geógrafo Marco Túlio Martins, publicada em 2016. A tese traz à baila temáticas ligadas à Geografia dos Estados Maiores e sua ação sobre o território, especialmente aquelas associadas à modernização conservadora e autoritária. Essa ação ocorreu de acordo com a ótica capitalista. Não foi por mera coincidência que o autor utilizaria em seu resumo as seguintes palavras-chave: pensamento geográfico, formação territorial do Brasil, Exército, militares e território. Mesmo após quatro anos de sua publicação, a atualidade da tese se mostra fundamental, em particular no que tange ao alto grau de militarização, nos quadros do atual governo do presidente Jair Messias Bolsonaro, como jamais vistos desde a redemocratização desde o fim dos anos de 1980.

2 Em primeiro lugar, o autor, no desenvolvimento de sua escrita, vale-se do conceito de Formação Territorial sob a ótica do geógrafo Antônio Carlos Robert Moraes (2005), isto é, aquele que supera a conceituação clássica do conceito de território em si. Dessa maneira, há outros componentes que norteiam a dimensão desse conceito, como as 
noções de política, direito, economia e cultura. Nesse conceito, Estado e história aparecem de modo imbricado (MARTINS, 2016).

3 Ficou evidente que o autor utilizou diferentes tipos de representações para realizar sua análise, uma vez que foram encontradas na tese uma infinidade de cartas, mapas e relatórios. Uma parte considerável das fontes documentais foram colocadas no anexo da obra. De um modo geral, seus escritos se debruçaram sobre os arquivos documentais do Exército, em especial àqueles referentes ao extinto Ministério da Guerra e do Arquivo Histórico do Exército.

Inicialmente a tese se amparou em três tópicos essenciais: Colônias Militares, as Linhas Telegráficas e as Vias de comunicação, que nortearam seus cinco capítulos: 1ํ) Formação Territorial Brasileira e sua Geo-História Militar, de 1889 a 1945; 2) O Estado, as instituições militares do Exército e os estudos sobre o território brasileiro: o destaque para a cartografia; $3^{\circ}$ ) As colônias $e$ as regiões militares: a geoestratégia do Exército; $\left.4^{\circ}\right)$ As linhas Telegraphicas Militares: um projeto para a modernidade; e, por último, 5) 0 Projeto Viário dos militares: caminhos, estradas e ferrovias.

5 No primeiro capítulo, sobre a "Formação Territorial Brasileira e sua Geo-História Militar: 1889 a 1845", inicialmente o autor procurou demonstrar a evolução e a solidificação histórica do Exército, desfrutando da análise de diferentes historiadores da História Militar do Brasil, procurando estar atento às contribuições desses intelectuais no que tange à formação territorial brasileira. Além do mais, lembra o autor, que a inserção dessa instituição no processo de formação territorial brasileira nem sempre atendeu aos interesses das diferentes oligarquias regionais que tinham em seu favor a extinta Guarda Nacional em detrimento do Exército no Brasil - Império (XIX). Nesse período o Exército ficara relegado ao ostracismo, situação esta modificada entre o final do século XIX e as três primeiras décadas do século XX. Naquela época a instituição teve seu ápice de atuação na geopolítica de cunho nacionalista do período Vargas. De acordo com o autor, cabe lembrar que uma estrutura territorial moldada sob uma modernização conservadora visou a dar um papel mais fluido aos fluxos capitalistas estrangeiros, coadunado com os interesses das classes dirigentes e industriais do país.

6 No segundo capítulo, intitulado "O Estado, as instituições militares do Exército e os estudos sobre o território brasileiro: o destaque para a cartografia", teve como objetivo demonstrar quais foram as filiais institucionais do Exército responsáveis pelos estudos realizados acerca do território, em particular aquelas que davam enfoque ao conhecimento cartográfico. Levou-se em consideração a interação dessas filiais militares com algumas instituições civis, estas últimas agindo em função do projeto da geoestratégia militar, iniciado com vigor entre as duas Primeiras Repúblicas indo até o Estado Novo.

7 Sendo assim, o autor considera as seguintes características sobre a Geografia Militar colocada em prática naquele período: primeiro atribui a esta elementos pertencentes a Geografia Tradicional, por contemplar prioritariamente a descrição, a coleta de dados, o trabalho de campo pautado na observação e no ideal positivista; segundo, a classificou como a Geografia dos Estados Maiores, visto que, em sua essência, incorporava traços da geoestratégia sobre o território nacional. Nesse sentido, a Geografia Militar se diferiria da Geografia Acadêmica quanto as suas práticas.

8 O terceiro capítulo, "As colônias e as regiões militares: a geoestratégia do Exército", trata sobretudo sobre a evolução e consolidação das Colônias Militares (CM) e das Regiões Militares (RM) em duas áreas fundamentais do território nacional, a saber: no Norte e no Sul. As CM, ao longo das décadas, deram as bases para a interiorização das diferentes 
Unidades Militares nas áreas estratégicas. A implantação e o desenvolvimento dessas colônias de origem militar originaram-se a partir do século XIX e culminaram na Era Vargas. Três ideais essenciais foram norteadores dessas filiais militares. A primeira delas foi de origem geoestratégica, por concentrar esforços na vigilância e controle do território em um período em que houve litígio com as lindes fronteiriças com os países do sul. A segunda de ordem econômica, priorizou o povoamento, o desenvolvimento industrial e agrícola priorizando os fluxos. Isto ocorreu procurando estruturar as bases para as futuras vias de comunicações que seriam criadas no sertão, em particular na região norte. E a terceira, de caráter político, fez declinar o poder das diferentes oligarquias regionais que de alguma maneira poderiam causar algum tipo de embate que fossem ao encontro dos interesses do Estado. Nesta linha de pensamento, sobre a consolidação destas filiais e o enfraquecimento das oligarquias regionais, disse o autor: “(...) Por isso, o Exército foi se aproveitando do conhecimento do todo sobre a materialidade $e$ articulando os acúmulos que levaram às fissuras das oligarquias regionais" (MARTINS, 2016, p. 115).

9 No quarto capítulo, em "As linhas Telegraphicas Mlitares: um projeto para a modernidade", o autor debruçou-se sobre a análise da construção das Linhas Telegráficas instaladas pelos militares. Essa construção por diferentes comissões, como resultado, forneceu subsídios ao estudo do território por onde essas linhas atravessassem, em especial os "sertões", tal como o aprimoramento do conhecimento cartográfico, o estudo do solo, da flora e da fauna destas regiões. Enfatizou, entretanto, que o papel fundamental da implantação das Linhas Telegráficas foi o de modernizar e dar unidade à incipiente rede de comunicações do país.

10 Por fim, o quinto e último capítulo, intitulado "O Projeto Viário dos militares: caminhos, estradas e ferrovias", apresenta os projetos de transportes dos militares, que atendeu aos interesses da base oligárquica cafeeira quanto ao papel de soberania, defesa e integração nacional. 0 projeto viário militar visou a interligação das regiões interioranas das áreas litorâneas mais dinâmicas, em particular, a ferrovia e a rodovia, diante da grande extensão territorial brasileira. Assim, ficou latente o papel modernizador das rotas de comunicação viária até a década de 1930, até mesmo concedendo subsídios à modernização da indústria nacional.

11 Conforme demonstrado pelo autor neste capítulo, a elite agropecuária procurou participar da ampliação ferroviária, principalmente no Rio Grande do Sul, Rio de Janeiro, São Paulo e Espírito Santo. Consequentemente, o Sudeste foi mais bem equipado, devido à construção das diferentes vias férreas ao longo da costa litorânea $\mathrm{e}$ do papel político exercido pela elite cafeeira. Desse modo, as obras viárias referentes à expansão ferroviária, além de atender à geoestratégia da defesa militar em voga, nesse caso, acompanhou o interesse desta oligarquia regional.

Por outro lado, as rodovias já estavam em expansão desde 1920, intensificando-se na década seguinte, quando os projetos ferroviários entrariam em declínio. A nova realidade visava a maiores fluxos de integração no território e, com isso, a ferrovia ficou relegada a um papel de mera exportação. Os principais planos rodoviários - Plano Catambry ou Plano Geral Rodoviário do Brasil (1926), Plano Paulo de Frontin (1927) e Plano Schnoor (1927) - tiveram a participação direta ou indireta de engenheiros militares. Esses planos, apesar de não terem sido realizados pelo Estado brasileiro naquele momento, nortearam outros planos de ação de cunho rodoviário pelo País em tempos futuros. Na mesma linha de raciocínio, teve um papel de destaque a carta exposta na 
tese, que se intitula Vias de Comunicação de Maior Importância Militar, de 1934. Observouse nela a importância que os militares davam ao fato de manterem o estabelecimento da malha ferroviária. Concomitante a esse fato, verificaram-se a disseminação e o estabelecimento das novas estradas de rodagem país afora.

Os diferentes modos de arguição realizados por Marco Túlio Martins (2016) por diferentes tipos de interpretação e da análise de cartas e relatórios do Exército - em particular do Ministério da Guerra e do Arquivo Histórico do Exército - levaram o autor a considerar a ação militar no que se refere ao ordenamento territorial brasileiro. 0 primeiro momento de exame dos documentos se referiu ao papel dos militares no que tange à defesa nacional; já o segundo momento, à integração e unidade nacional. Diante dos cursos que a nação tomara, notou-se que uma pequena participação da sociedade civil, isto é, passiva sobre o ordenamento espacial do período em questão (1889 - 1930), desta maneira a organização territorial ficou a cargo destes agentes estatais. Essa modelagem sobre a nação teve um caráter conservador e autoritário que se fez representar sobre a atual classificação regional do país.

Outrossim, levando-se em consideração os fatos mencionados, a tese do geógrafo Marco Túlio Martins (2016) tem se apresentado relevante aos geógrafos, visto que se aproxima da vertente relacionada à história da geografia e do pensamento geográfico. Essa realidade está imbricada aos saberes geográficos inseridos nas escolas de militares desde o século XIX, momento anterior à sistematização da geografia acadêmica brasileira. De acordo com o autor, alguns pesquisadores têm se debruçado sobre a temática que envolveu a ação desses agentes militares no período mencionado. Entre eles destacam-se sobretudo cientistas políticos, sociólogos e historiadores, como Leonardo Trevisan (1993), Edmundo C. Coelho (1976), Cláudia Alves (2002; 2006), e Frank McCann (2007). Nesse sentido, poucos geógrafos têm dedicado espaço em suas pesquisas para a relação entre o saber geográfico, território e a ação militar, como por exemplo: Yves Lacoste (1988), sobre a geografia dos Estados Maiores; sobre a formação militar e o saber geográfico; Filipe Dal Bo Ribeiro (2015), sobre a geografia militar e a defesa nacional; e Sérgio Nunes Pereira (1997), sobre "Geografia: lugares e caminhos da produção do saber geográfico no Brasil". Nessa linha de pensamento, ainda há a necessidade de os geógrafos ampliarem seu lócus de discussão a respeito da contribuição das implicações das ações dos agentes militares sobre o território dentro do recorte temporal tratado pelo autor em sua tese. A pouca atenção dada à temática até então pode estar relacionado ao passado sombrio em que vigorou a presença de militares em regimes autoritários e ditatoriais, em especial durante o Estado Novo e no Golpe de 1964 que deu andamento a Ditadura Militar que vigorou por mais de 20 anos. 


\section{AUTHOR}

RAPHAEL NEVES DA CONCEIÇÃO

Mestre em Geografia pela Universidade Federal Fluminense (pólo Campos dos Goytacazes).

Docente em geografia da SME do município do Rio de Janeiro. Membro do Grupo de Pesquisa

Política, Epistemologia e História da Geografia (LAHPEGE/UFRRJ).E-mail:rapha_nc@hotmail.com 